This item was submitted to Loughborough's Research Repository by the author.

Items in Figshare are protected by copyright, with all rights reserved, unless otherwise indicated.

\title{
A simple theoretical model of heat and moisture transport in multi-layer garments in cool ambient air
}

PLEASE CITE THE PUBLISHED VERSION

http://dx.doi.org/10.1007/s00421-008-0966-5

PUBLISHER

(C) Springer

VERSION

AM (Accepted Manuscript)

LICENCE

CC BY-NC-ND 4.0

REPOSITORY RECORD

Wissler, Eugene H., and George Havenith. 2019. "A Simple Theoretical Model of Heat and Moisture Transport in Multi-layer Garments in Cool Ambient Air". figshare. https://hdl.handle.net/2134/9745. 
This item was submitted to Loughborough's Institutional Repository (https://dspace.lboro.ac.uk/) by the author and is made available under the following Creative Commons Licence conditions.

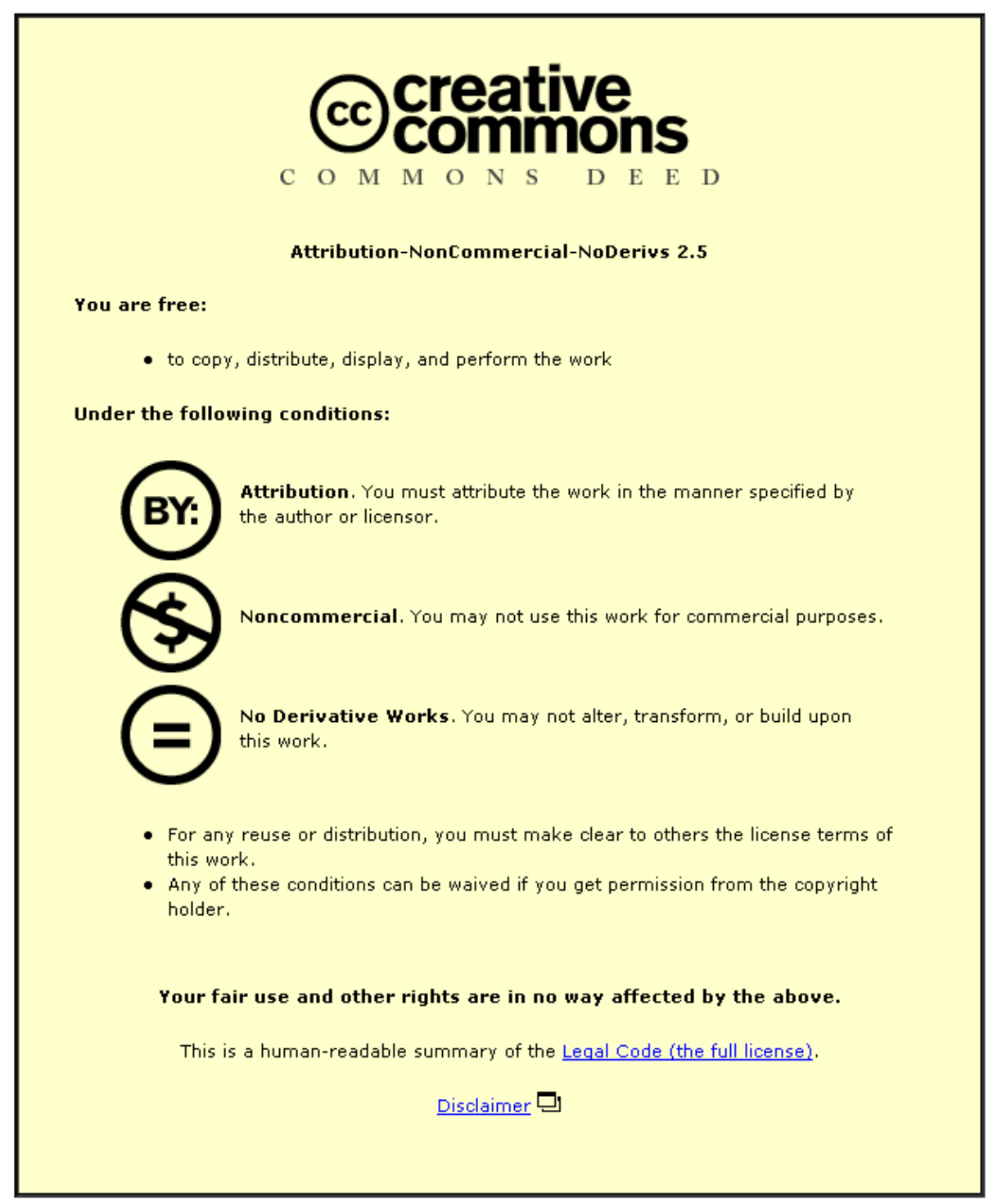

For the full text of this licence, please go to: http://creativecommons.org/licenses/by-nc-nd/2.5/ 


\title{
A Simple Theoretical Model of Heat and Moisture Transport in Multi-layer Garments in Cool Ambient Air
}

\author{
Eugene H. Wissler \\ Department of Chemical Engineering \\ The University of Texas at Austin \\ Austin, Texas, USA \\ George Havenith \\ Environmental Ergonomics Research Group \\ Department of human sciences \\ Loughborough University \\ Loughborough LE11 3TU, UK
}

Tel. No.: (936) 597-9233

e-mail: ehwissler@mail.utexas.edu 


\begin{abstract}
Overall resistances for heat and vapour transport in a multilayer garment depend on the properties of individual layers and the thickness of any air space between layers. Under uncomplicated, steady-state conditions, thermal and mass fluxes are uniform within the garment, and the rate of transport is simply computed as the overall temperature or water concentration difference divided by the appropriate resistance. However, that simple computation is not valid under cool ambient conditions when the vapour permeability of the garment is low, and condensation occurs within the garment.

Several recent studies have measured heat and vapour transport when condensation occurs within the garment (Richards, et al., 2002, and Havenith, et al., 2008). In addition to measuring cooling rates for ensembles when the skin was either wet or dry, both studies employed a flat-plate apparatus to measure resistances of individual layers. Those data provide information required to define the properties of an ensemble in terms of its individual layers.

We have extended the work of previous investigators by developing a rather simple technique for analyzing heat and water vapour transport when condensation occurs within a garment. Computed results agree well with experimental results reported by Richards, et al. (2002) and Havenith, et al. (2008). We discuss application of the method to human subjects for whom the rate of sweat secretion, instead of the partial pressure of water on the skin, is specified. Analysis of a more complicated five-layer system studied by Yoo and Kim (2008) required an iterative computation based on principles defined in this paper.
\end{abstract}

Keywords: protective garments, sweat evaporation, condensation, cooling efficiency 


\section{Introduction}

Heat transfer through clothing owing to evaporation from skin with condensation in cool outer regions of the garment is discussed in a recent paper by Havenith, et al. (2008). Sensible heat transfer by conduction and radiation down the temperature gradient from skin to ambient air and diffusion of water vapour down the water partial pressure gradient provide parallel pathways for heat removal from the skin. When the outer garment has a low permeability for water vapour and the ambient temperature is sufficiently low, condensation may occur within the garment increasing the rate of enthalpy transport from skin by diffusing water vapour and decreasing the thermal flux owing to conduction and radiation. Several interesting features of that process are described in detail by Havenith, et al. In particular, they discuss the considerable error that can occur when the rate of evaporative heat loss from skin is computed solely as the product of the rate of weight loss of the clothed subject and the latent heat of vaporization of water. Those errors can dramatically decrease the accuracy of prediction of heat tolerance limits based on heat balance calculations (e.g. ISO 7933). Havenith, et al. (2008) established that the effect of condensation observed in the simple, cylindrical, two-layer garments studied by Richards, et al (2002) was also observed when similar garments were evaluated on a human manikin.

In addition to discussing factors involved in moisture transport through clothing, Havenith, et al. and Richards, et al. tabulated resistances for sensible and evaporative heat transfer for individual layers measured using a flat-plate system. However, they did not compute the overall resistance of their garments from the resistances of individual layers. In this paper we show that application of fundamental principles of heat and mass transfer allows one to analyze heat transfer with condensation in a multilayer garment using the properties of individual garment layers.

Havenith, et al. introduced and discussed their experimental data in terms of two different evaporative cooling efficiencies. While those variables are conceptually interesting, their practical utility is limited because they are not defined in terms of clothing properties and conditions on the skin and in ambient air. A conceptually elegant, but computationally demanding, analysis of moisture transport in clothing was described in 1986 by Farnworth, and a much simpler quasi-steady-state analysis was published in 1995 by Lotens, et al. The approach developed by Lotens, et al. was modified by Fukazawa, et al. (2003b) to obtain an analytical solution, although the final result still appears to involve some computation. Both papers compare theoretical results with experimental data. Lotens, et al. verified the essential correctness of their model by showing that computed results were in substantial agreement with three sets of data for human subjects who performed both light and heavy exercise while wearing either a semi-permeable or an impermeable outer garment. Fukazawa, et al. (2003b) validated their model by showing that calculated mass fluxes were in good agreement with fluxes measured in a flat-plate apparatus (Fukazawa, et al., 2003a). Temperature, water vapour pressure, and total pressure (which affects the resistance to mass transfer) were varied 
over a considerable range of conditions. The studies of Lotens, et al. and Fukazawa, et al. lend credence to the analysis presented in this paper.

The purposes of the present paper are: (1) to demonstrate that the method developed by Lotens, et al. (1995) provides a rational explanation for the results observed by Havenith, et al (2008), and (2) to extend applicability of the method to systems other than those considered by Lotens, et al. and Fukazawa, et al. We compare heat transfer rates computed using clothing properties derived from flat-plate data with heat transfer rates measured on a clothed manikin. Although manikin data involve fewer extraneous factors than data generated with exercising human subjects, uneven distribution of air between the inner and outer garments still presents a significant problem. Therefore, data obtained using a two-fabric cylindrical system with a known distance between fabrics provide a better test of theoretically derived relationships. Fortunately, such data are now available (Richards, et al. 2002).

The principal difference between our approach and the approaches employed by Lotens, et al. (1995) and Fukazawa, et al. (2003b) is that neither of those authors considered the effect of an air space separating inner and outer garments, and they assumed a priori that condensation occurs at a particular location within the garment. Lotens, et al. assumed that condensation occurs at the inner garment-outer garment interface when the outer garment permeability for water vapour is much lower than the permeability of the inner garment. Similarly, Fukazawa, et al. (2003) made the rather restrictive assumption that condensation occurs on the external surface of the garment. Although the assumptions made by Lotens, et al. and by Fukazawa, et al. are often appropriate, situations exist in which they are inappropriate. An example of a more complicated system is provided by the five-fabric ensemble studied by Yoo and Kim (2008). We show that the method presented in this paper is also applicable that system.

Results presented in this paper define in physical terms the complementary nature of conduction, radiation, diffusion of water vapour, and condensation within the garment. Although our analysis is straightforward and easily applied to simple two-layer garments, its application to exercising subjects will require additional analysis, because we have neglected several factors that may become increasingly important as moisture accumulates in the garment. Nevertheless, application of analytical methods based on the concepts presented in this paper will reduce potentially large errors and erroneous risk assessments that may otherwise occur.

\section{Method - theoretical analysis}

Garments typically consist of several layers separated by air spaces. Although the temperature and partial pressure of water are continuously variable within the garment, we will compute their values at a small number of discrete points, or nodes.

\section{Figure 1 near here}


Four nodes are defined for the typical two-layer garment shown in Figure 1. Node 1 is at the skin-underwear interface; Node 2 is at the outer surface of the underwear; Node 3 is at the inner surface of the outer garment; and Node 4 is at the outer surface of the garment. An air space between Nodes 2 and 3 separates the two layers. Node 5 represents ambient conditions. The temperature $\left(\mathrm{T}_{\mathrm{i}}\right)$ and partial pressure of water $\left(\mathrm{p}_{\mathrm{i}}\right)^{1}$ are defined at each node. The resistance to sensible heat transfer between Nodes $\mathrm{i}$ and $i+1$ is $R_{c, i}$, and the corresponding resistance to water vapour transport is $R_{e, i}$. Assuming that the temperature and partial pressure of water are specified at Nodes 1 and 5 (that is, on the skin and in ambient air) the problem is to compute the rate of heat transfer from skin owing to conduction, radiation, and evaporation of water. The partial pressure of water at Node 1 depends on conditions on the skin, and will be dealt with later.

The rate of sensible heat transfer $\left(Q_{c, i}\right)$ from left to right away from Node $i$ is given by

$$
Q_{c, i}=\frac{T_{i}-T_{i+1}}{R_{c, i}},
$$

and the corresponding rate of heat transfer owing to water transport $\left(\mathrm{Q}_{\mathrm{e}, \mathrm{i}}\right)$ is

$$
Q_{e, i}=\frac{p_{i}-p_{i+1}}{R_{e, i}}
$$

A complete list of symbols appears in Table 10 at the end of the paper.

Values of $R_{c}$ and $R_{e}$ for individual garment layers are typically determined using a flat plate device in which the rates of sensible heat transfer and heat transfer owing to water transport are measured for known temperature and humidity differences across the garment. Resistances of air spaces and the boundary layer on the external surface of the garment are usually computed.

Heat is transferred across a stagnant air layer by two mechanisms - conduction and radiation (Bird, et al., 2001). The combined rate is

$$
Q_{a}=\left[\frac{k_{a}}{x_{a}}+\sigma \varepsilon\left(T_{i}^{2}+T_{1+1}^{2}\right)\left(T_{i}+T_{i+1}\right)\right]\left(T_{i}-T_{i+1}\right)
$$

${ }^{1}$ In this paper, the partial pressure of water, $\mathrm{p}_{\mathrm{i}}$, is the product of the mole fraction of water and the total pressure. The vapour pressure of water, $\mathrm{p}_{\mathrm{v}, \mathrm{i}}$, is defined as the pressure of water vapour in equilibrium with liquid water. It is a function of temperature. 
Hence,

$$
R_{c, a}=\left[\frac{k_{a}}{x_{a}}+\sigma \varepsilon\left(T_{i}^{2}+T_{1+1}^{2}\right)\left(T_{i}+T_{i+1}\right)\right]^{-1} .
$$

Similarly, diffusion of water across an air space occurs at the rate,

$$
E_{a}=\left(D / x_{a}\right) \rho_{H_{2} O} \frac{273}{T_{a}} \frac{\left(p_{i}-p_{i+1}\right)}{p_{o}} .
$$

It follows that

$$
R_{e, a}=\frac{x_{a} T_{a} p_{o}}{273 D \rho_{\mathrm{H}_{2} \mathrm{O}} \lambda}
$$

Heat transfer from the external surface to ambient air by convection and to walls by radiation has been measured by various investigators (for example, Nishi and Gagge, 1970, deDear, et al., 1992). When air and wall temperatures are identical, the resistance to transfer of sensible heat from the external surface of the garment is computed as follows:

$$
R_{c, b l}=\frac{1}{h_{c}+h_{r}}
$$

Given $h_{c}$ the mass transfer coefficient for water vapour transport can be computed using the analogy between heat and mass transport. It follows that

$$
R_{e, b l}=\frac{1}{C_{L} h_{c}}
$$

in which $\mathrm{C}_{\mathrm{L}}$ is the Lewis coefficient.

Values of $R_{c}$ and $R_{e}$ for elements of several garments evaluated by Havenith, et al. (2008) appear in Table 1. In several examples used to illustrate the method described in the paper, we employ a particular garment (the Reference Garment) similar to one of the garments studied by Havenith, et al. (2008). The Reference Garment consists of a polypropylene undergarment and an impervious outer garment separated by a $1 \mathrm{~mm}$ air space; the four elements of the Reference Garment are designated by asterisks in Table 1. It is interesting to note that a large fraction of the total resistance for sensible heat transfer is attributable to the air space between layers and the external boundary layer.

Table 1 near here 
When there is no condensation within the garment, the rate of evaporative cooling of the skin $\left(Q_{e, 1}\right)$ is simply

$$
Q_{e, 1}=\frac{p_{1}-p_{5}}{\hat{R}_{e, 4}}
$$

where $\hat{R}_{e, i}=\sum_{j=1}^{j=i} R_{e, j}$.

In the absence of condensation, the partial pressure of water at Node $\mathrm{i}$ is given by the relationship,

$$
p_{i}=p_{1}-\left(p_{1}-p_{5}\right) \frac{\hat{R}_{e, i-1}}{\hat{R}_{e, 4}} .
$$

Similarly, without condensation in the garment, the rate of sensible heat transfer from the skin $\left(Q_{c, 1}\right)$ is

$$
Q_{c, 1}=\frac{T_{1}-T_{5}}{\hat{R}_{c, 4}}
$$

where $\hat{R}_{c, i}=\sum_{j=1}^{j=i} R_{c, j}$.

The temperature at Node $\mathrm{i}$ is then computed as follows

$$
T_{i}=T_{1}-\left(T_{1}-T_{5}\right) \frac{\hat{R}_{c, i-1}}{\hat{R}_{c, 4}} .
$$

Given $\mathrm{T}_{\mathrm{i}}$ one can compute the vapour pressure of water, $\mathrm{p}_{\mathrm{v}, \mathrm{i}}$. As long as $\mathrm{p}_{\mathrm{i}}<\mathrm{p}_{\mathrm{v}, \mathrm{i}}$, condensation does not occur at the node.

A more interesting situation occurs when conditions are such that $\mathrm{p}_{\mathrm{v}, \mathrm{i}}<\mathrm{p}_{\mathrm{i}}$ (where $\mathrm{p}_{\mathrm{i}}$ is defined by Eqn. 11) at one or more nodes within the garment. Then, condensation occurs within the garment and $\mathrm{p}_{\mathrm{i}}=\mathrm{p}_{\mathrm{v}, \mathrm{i}}$ at the node (or nodes) where condensation occurs. The temperature at a node where condensation occurs increases owing to release of latent heat, which, in turn, reduces the rate of sensible heat transfer from skin to the node and increases the rate of heat transfer from the node to the external surface of the garment.

The possibility of condensation within a garment gives rise to several questions. One is, given the boundary conditions $\left(T_{1}, p_{1}, T_{5}\right.$ and $\left.p_{5}\right)$ does condensation occur within the garment? If so, where does it occur, and what are the values of $\mathrm{T}_{\mathrm{i}}, \mathrm{p}_{\mathrm{i}}$, and the water vapor fluxes $\left(\mathrm{E}_{\mathrm{i}-1}\right.$ and $\left.\mathrm{E}_{\mathrm{i}}\right)$ at the node where condensation occurs? If skin and ambient conditions are such that condensation occurs within the garment, it must occur when the skin is wet and $p_{1}=p_{v, 1}$, although it may also occur when the skin is not fully wet; $i$. e, when $\mathrm{p}_{1}<\mathrm{p}_{\mathrm{v}, 1}$. 
To determine whether condensation occurs for the limiting condition of wet skin and, if so, where it occurs we compute $T_{i}$ and $p_{i}-p_{v, i}$ at each node using Eqns. 11 and 14 with $\mathrm{p}_{1}=\mathrm{p}_{\mathrm{v}, 1}$. If $\mathrm{p}_{\mathrm{v}, \mathrm{i}}<\mathrm{p}_{\mathrm{i}}$ at any node, condensation occurs in the garment when the skin is wet. In simple garments such as the one illustrated in Fig. 1, condensation occurs at the node where $p_{i}-p_{v, i}$ has its largest value. Let that node be Node ic. After the temperature and vapor pressure of water have been computed at Node ic as described below, one should check to make certain that $p_{i} \leq p_{v, i}$ at all other nodes.

An alternative approach to determining whether and where condensation occurs in a garment is to compute the minimum value of $\mathrm{p}_{1, \mathrm{~m}}$ for which condensation occurs at each node. Solving Eqn. 11 with $p_{i}=p_{v, i}$, the vapor pressure of water at $T_{i}$ defined by Eqn. 14, yields the result

$$
p_{1, m}=\frac{p_{v, i} \hat{R}_{e, 4}-p_{5} \hat{R}_{e, i-1}}{\hat{R}_{e, 4}-\hat{R}_{e, i-1}} .
$$

Since the partial pressure of water at each node is proportional to $\mathrm{p}_{1}$ in the absence of condensation, condensation with increasing $\mathrm{p}_{1}$ occurs first at the node where $\mathrm{p}_{1, \mathrm{~m}}$ defined by Eqn. 15 has its minimum value. However, if $\mathrm{p}_{1}$ is much larger than the value defined by Eqn. 15, condensation may also occur at other nodes. A computational scheme for dealing with more complex situations in which condensation occurs at several nodes is discussed later.

Presented in Table 2 are the temperature, partial pressure of water, and heat transfer rates at each node in the Reference Garment when the skin temperature is $34{ }^{\circ} \mathrm{C}$ and $\mathrm{p}_{1}=\mathrm{p}_{\mathrm{v}, 1}$. The ambient temperature and partial pressure of water are $10{ }^{\circ} \mathrm{C}$ and $1 \mathrm{kPa}$, respectively. Two different conditions are shown: the first hypothetical condition assumes that condensation does not occur in the garment, and the second condition allows condensation to occur at Node 3. Computation of values with condensation is discussed in the next section. Without condensation, the principal mode of heat transfer from the skin is sensible heat transfer with $\mathrm{Q}_{\mathrm{c}, 1}=96.2 \mathrm{~W} / \mathrm{m}^{2}$, and evaporative cooling, $\mathrm{Q}_{\mathrm{e}, 1}$, contributes only $4.2 \mathrm{~W} / \mathrm{m}^{2}$. If we had assumed that the resistance for water vapor transport through the outer garment was infinite instead of $1,000 \mathrm{~m}^{2} \mathrm{~Pa} / \mathrm{W}$, evaporative cooling would have vanished. With condensation at Node $3, \mathrm{~T}_{3}$ increases from $19.9{ }^{\circ} \mathrm{C}$ to $25.0{ }^{\circ} \mathrm{C}$, and $\mathrm{Q}_{\mathrm{c}, 1}$ is reduced to $61.8 \mathrm{~W} / \mathrm{m}^{2}$. In addition, $\mathrm{p}_{3}$ is reduced from $5.21 \mathrm{kPa}$ to $3.16 \mathrm{kPa}$, and $\mathrm{Q}_{\mathrm{e}, 1}$ increases to $85.5 \mathrm{~W} / \mathrm{m}^{2}$. Hence, condensation at Node 3 increases the total rate of skin cooling from $100.4 \mathrm{~W} / \mathrm{m}^{2}$ to $147.3 \mathrm{~W} / \mathrm{m}^{2}$.

\section{Table 2 near here}

The manner in which condensation affects the water partial pressure and temperature distributions in the Reference Garment is illustrated in Fig. 2 where partial pressure is plotted against the garment temperature at each node. Node 1 is at $34{ }^{\circ} \mathrm{C}$ and Node 5 is at $10{ }^{\circ} \mathrm{C}$. The heavy solid line is the temperature-vapour pressure curve for water. Solid circles denote the hypothetical condition in which there is no condensation. 
Without condensation the partial pressure of water on the inside of the nearly impervious outer garment would be $5.21 \mathrm{kPa}$, which is not much different from the partial pressure of water on the skin, and there is a very sharp drop in partial pressure across the outer garment. Solid triangles denote condensation at Node 3. With condensation on the inner surface of the outer garment, the partial pressure of water at Node 3 is reduced to 3.16 $\mathrm{kPa}$, the vapour pressure of water at $25^{\circ} \mathrm{C}$. Since $\mathrm{p}_{2}$ is slightly larger than $\mathrm{p}_{\mathrm{v}, 2}$, a small amount of condensation probably occurs in the underwear.

Also shown as open triangles in Fig. 2 are partial pressures when the $\mathrm{p}_{1}=2.36$ $\mathrm{kPa}$, the minimum value for which condensation occurs in the garment. For that case, $\mathrm{p}_{\mathrm{i}} \ll<\mathrm{p}_{\mathrm{v}, \mathrm{i}}$ at all nodes except Node 3 .

\section{Figure 2 near here}

Analysis of heat and water transport in a simple garment like the Reference Garment is not difficult. After the node where condensation occurs has been identified as described previously, values of the unknowns, $T_{i c}, p_{i c}=p_{v, i c}$, and the rate of condensation $\left(\dot{m}_{i c}\right)$ are defined by a material balance for water at Node ic, an energy balance at Node ic, and the temperature-vapour pressure relationship for water. The material balance is written as follows:

where

$$
E_{1}-E_{i c}=\dot{m}_{i c}
$$

$$
\begin{aligned}
& E_{1}=\frac{p_{1}-p_{v, i c}}{\lambda \hat{R}_{e, i c-1}}, \text { and } \\
& E_{i c}=\frac{p_{v, i c}-p_{5}}{\lambda\left(\hat{R}_{e, 4}-\hat{R}_{e, i c-1}\right)} .
\end{aligned}
$$

The energy balance has the form

$$
\frac{T_{1}-T_{i c}}{\hat{R}_{c, i c-1}}+\lambda \dot{m}_{i c}=\frac{T_{i c}-T_{5}}{\hat{R}_{c, 4}-\hat{R}_{c, i c-1}} .
$$

Algebraically eliminating $\mathrm{E}_{1}, \mathrm{E}_{\mathrm{ic}}$, and $\dot{m}_{i c}$ from Eqns. $16-19$ yields the following linear relationship between $\mathrm{p}_{\mathrm{v}, \text { ic }}$ and $\mathrm{T}_{\mathrm{ic}}$.

$$
p_{v, i c}\left(\frac{1}{\hat{R}_{e, 4}-\hat{R}_{e, i c}}+\frac{1}{\hat{R}_{e, i c-1}}\right)=\left(\frac{p_{5}}{\hat{R}_{e, 4}-\hat{R}_{e, i c}}+\frac{p_{1}}{\hat{R}_{e, i c-1}}\right)+\left(\frac{T_{5}-T_{i c}}{\hat{R}_{e, 4}-\hat{R}_{e, i c}}+\frac{T_{1}-T_{i c}}{\hat{R}_{e, i c-1}}\right)
$$

Values of $T_{i c}$ and $p_{v, \text { ic }}$ that simultaneously satisfy Eqn. 20 and the temperature-vapour pressure relationship are easily determined as the intersection of the straight line defined 
by Eqn. 20 with the temperature-vapour pressure relationship for water. That is illustrated in Fig. 3 for the Reference Garment.

\section{Figure 3 near here}

The total rate of heat removal from the skin $\left(\mathrm{Q}_{\mathrm{sk}}\right)$ is the sum of the rates of sensible heat transfer from the skin and evaporative cooling of the skin. Hence,

$$
Q_{s k}=\frac{T_{1}-T_{i c}}{\hat{R}_{c, i c-1}}+\frac{p_{v, 1}-p_{v, i c}}{\hat{R}_{e, i c-1}} .
$$

Normally sweat is secreted at a rate (SR) determined by the thermal state of the individual. When SR instead of $p_{v, 1}$ is specified, two conditions are possible. If $\lambda \mathrm{SR}$ is less than the maximum possible rate of evaporative cooling $\left(Q_{e, 1, \max }\right)$, for which $\mathrm{p}_{1}=\mathrm{p}_{\mathrm{v}, 1}$, $\mathrm{Q}_{\mathrm{e}, 1}=\lambda \mathrm{SR}$, and $\mathrm{p}_{1}<\mathrm{p}_{\mathrm{v}, 1}$. On the other hand, if $\mathrm{Q}_{\mathrm{e}, 1, \max }<\lambda \mathrm{SR}, \mathrm{Q}_{\mathrm{e}, 1}=\mathrm{Q}_{\mathrm{e}, 1, \max }, \mathrm{p}_{1}=\mathrm{p}_{\mathrm{v}, 1}$, and excess sweat accumulates on the skin. As SR increases from a minimal rate corresponding to insensible perspiration, $\mathrm{Q}_{\mathrm{e}, 1}$ and $\mathrm{p}_{1}$ increase correspondingly, and

$$
p_{1}=p_{5}+S R \hat{R}_{e, 4}
$$

until condensation occurs either on the skin, or within the garment.

The effect of condensation within the garment when $\mathrm{p}_{1}<\mathrm{p}_{\mathrm{v}, 1}$ is illustrated by computing the rate of skin cooling as a function of $\mathrm{p}_{1}$ for fixed values of the other parameters. Results computed for the Reference Garment are plotted in Fig. 4. Relevant parameters are: $\mathrm{T}_{1}=34{ }^{\circ} \mathrm{C}, \mathrm{T}_{5}=10{ }^{\circ} \mathrm{C}, \mathrm{p}_{5}=1.0 \mathrm{kPa}$, and the relative humidity at the skin-inner garment interface varies from 20 to 100 percent $\left(\mathrm{p}_{1}=1.07\right.$ to $\left.5.33 \mathrm{kPa}\right)$.

The nearly horizontal heavy line with the extended light line is the total rate of sensible and evaporative heat loss from skin assuming that no condensation occurs within the garment. Since the outer garment is almost totally impervious, there is very little evaporation from the skin without condensation within the garment, and the skin becomes totally wet at a relatively low rate of sweat secretion.

The rapidly rising heavy line is the rate of sensible plus evaporative heat loss from the skin when condensation occurs at Node 3 on the inside of the outer garment. Note that condensation initially occurs when the partial pressure of water on the skin $=2.36$ $\mathrm{kPa}$, which we noted previously is the minimum partial pressure of water on the skin for which condensation occurs in the garment. Results shown in Fig.4 illustrate clearly that condensation within the garment greatly facilitates evaporation from the skin and increases the sweat rate required to produce a relative humidity of 100 percent on the skin. The rate of evaporative cooling without condensation varies from 0.9 to only 2.3 $\mathrm{W} / \mathrm{m}^{2}$, while evaporative cooling with condensation at Node 3 , it increases from 0.9 to $53.4 \mathrm{~W} / \mathrm{m}^{2}$ as the relative humidity on the skin increases from 50 to 100 percent. The relative humidity on the skin remains below 100 percent as long as the rate of sweat 
secretion is below the maximum possible rate of evaporation with condensation within the garment.

\section{Results - comparison of computed and measured values}

Manikin experiments of Havenith, et al (2008)

We will first compare computed results with measured values reported by Havenith, et al. (2008). Three different undergarments (cotton, polyester, and polypropylene) were combined with three outer garments, characterized as permeable, semi-permeable, and impermeable. Transport properties of individual garments were measured using a flat-plate system. Since resistances of the undergarments for heat and water transport were quite similar, differences between their responses to given conditions were small. Properties of a representative undergarment and the three outer garments are given in Table 1. Although the resistance for heat transfer owing to diffusion of water vapor through the impervious outer garment per se is infinite, it was assigned a value of $1,000 \mathrm{~m}^{2} \mathrm{~Pa} / \mathrm{W}$ to allow partially for water transport through various openings in the garment. An air space $1 \mathrm{~mm}$ thick was assumed to separate the inner and outer garments. That thickness, which represents a mean value over the surface of the manikin, was chosen because it yields values of the rate of dry heat transfer and the isothermal evaporative cooling rate close to the measured values.

One comparison that can be made is $\mathrm{E}_{\text {mass }}$ defined by Havenith, et al. as $\lambda$ times the rate of weight loss of the clothed manikin. Measured values obtained from Fig. 5 of the cited paper are given in Table 3. Values enclosed in parentheses were computed as $\lambda$ times the rate of water vapour transport at the external surface of the garment; that is, at Node 4.

\section{Table 3 near here}

Computed rates of sensible and evaporative heat transfer from the skin are summarized in Table 4, together with measured values taken from Fig. 4 of the paper by Havenith, et al. (2008). Also shown are values of the total rate of heat transfer, which is the quantity, actually measured on the manikin.

\section{Table 4 near here}

Sweating cylinder experiments reported by Richards, et al (2002)

As we noted earlier, comparison of computed values with values measured using human subjects or a manikin is difficult, because the thickness of air between layers of clothing varies over the surface of the body and is never measured. That problem does not exist when two garment layers are placed on a heated, sweating cylinder with a known separation between the layers. Although the cylindrical system is a poor representation of the human form, it yields valuable data for testing the theoretical concepts presented in this paper. It is of passing interest to note that a cylindrical system 
was used by Count Rumford in 1804 to evaluate the properties of clothing (Rumford, 1804).

Two different cylindrical systems were used in the studies reported by Richards, et al. (2002). The diameter of both cylinders was $30 \mathrm{~cm}$, but they had different lengths $30 \mathrm{~cm}$ in one case and $46 \mathrm{~cm}$ in the other. Both cylinders were positioned with vertical axes. The incident air velocity was $1 \mathrm{~m} / \mathrm{s}$ in both cases, but the wind direction was horizontal for the longer cylinder and vertically downward for the other cylinder. Different methods were used to distribute water on the skin and to measure the rate of condensation in the garments. Not surprisingly, there was considerable difference between results obtained with the two systems. For example, the rate of heat loss per unit area measured for the longer cylinder at an air temperature of $20{ }^{\circ} \mathrm{C}$ was 25 to 30 percent larger than the rate measured for the shorter cylinder. Computed results are compared with measured results for the longer cylinder, which are means of three replicate determinations. Heat and mass transfer coefficients for the external surface of the outer garment were computed assuming horizontal air flow.

\section{Table 5 near here}

Experiments were conducted with different clothing ensembles that consisted of two garments separated by an $8 \mathrm{~mm}$ air space. We will compare computed and measured results for two ensembles - the cotton undergarment combined with either the semipermeable or impermeable outer garment. Properties of the garments are listed in Table 5. Each ensemble was evaluated both with and without sweating and at two ambient air temperatures, 10 and $20{ }^{\circ} \mathrm{C}$. In all cases, the skin temperature was $35{ }^{\circ} \mathrm{C}$ and the ambient relative humidity was 65 percent. Computed results are compared with measured results in Table 6.

\section{Table 6 near here}

Five-fabric system of Yoo and Kim (2008)

The third system analyzed is described in a recent paper by Yoo and Kim (2008). They evaluated three garments each composed of five fabric layers separated by air spaces. Properties of that system are shown in Table 7. Sweating skin was simulated by spraying either 2 or $5 \mathrm{ml}$ of water onto an absorbent fabric in contact with a copper plate maintained at a temperature of $33{ }^{\circ} \mathrm{C}$. Conditions on the cold side of the garment were a temperature of $-15^{\circ} \mathrm{C}$ and a relative humidity of 20 percent. Although this was a transient-state experiment, a steady-state analysis is reasonable because conditions remained nearly constant during the first 40 minutes of the $2 \mathrm{ml}$ experiments, and during the entire 60 minute duration of the $5 \mathrm{ml}$ experiment. This study is particularly interesting because the resistance to moisture transport is not concentrated in the outer layer, as it was in the other two garments, and there is no reason to expect that water condenses only on the inner surface of the outer layer.

\section{Table 7 near here}


Assuming that condensation occurs at only one node did not yield a satisfactory solution for this complex system. There were several problems with the simple solution. One was that water partial pressures larger than the corresponding vapour pressure of water were computed at several nodes. Another was that the water transport rate on the outside of a node was sometimes larger than the rate on the inside of the node.

Difficulties described above were resolved by using an iterative scheme to compute a set of temperatures and partial pressures that satisfied three conditions: (1) Either

$$
\frac{p_{i-1}-p_{i}}{R_{e, i-1}}=\frac{p_{i}-p_{i+1}}{R_{e, 1}} \text { if } \mathrm{p}_{\mathrm{i}}<\mathrm{p}_{\mathrm{v}, \mathrm{i}} \text {, or } \mathrm{p}_{\mathrm{i}}=\mathrm{p}_{\mathrm{v}, \mathrm{i}}
$$

(2) The following energy balance is satisfied at each node.

$$
\frac{T_{i-1}-T_{i}}{R_{c, i-1}}-\frac{T_{i}-T_{i+1}}{R_{c, i}}+\left(\frac{p_{i-1}-p_{i}}{R_{e, i-1}}-\frac{p_{i}-p_{i+1}}{R_{e, 1}}\right)=0
$$

Note that the term within parentheses vanishes when there is no condensation at the node.

(3) The rate of vapour transport away from a node can be no larger than the rate of vapour transport toward the node.

$$
E_{i} \geq E_{i+1}
$$

Note that Eqns. 23 and 24 are equivalent to Eqns. 16 - 20.

Results computed using the procedure described above are summarized in Table 8. The subscript $\mathrm{i}$ identifies the node (defined in Table 7) at which the value is computed. For example, the column labeled Node 5 contains values on the inner surface of Fabric Layer 2, where the temperature is $21.24{ }^{\circ} \mathrm{C}$; the partial pressure and vapour pressure are both $2.52 \mathrm{kPa}$, which indicates that water has condensed in the layer; sensible heat is transferred toward that layer at the rate of $30.14 \mathrm{~W} / \mathrm{m}^{2}$, and water vapour diffusing toward the layer at a rate of $22.25 \mathrm{mg} /\left(\mathrm{m}^{2} \mathrm{~s}\right)$ transports enthalpy at the rate of 54.03 $\mathrm{W} / \mathrm{m}^{2}$. When values under Node 5 are compared with corresponding values under Node 6, we see that appreciable temperature and pressure drops occur across Fabric Layer 2. Since water vapour diffuses away from Fabric Layer 2 at only $19.01 \mathrm{mg} /\left(\mathrm{m}^{2} \mathrm{~s}\right)$, water condenses in Fabric Layer 2 releasing its latent heat of vaporization. Consequently, the rate of sensible heat transfer away from the layer $\left(38.00 \mathrm{~W} / \mathrm{m}^{2}\right)$ is larger than the rate of transfer toward the layer. Conversely, the rate at which enthalpy is carried by diffusing water vapour decreases as water condenses in the layer. The combined rate of enthalpy transport (that is, the sum of conductive, radiative, and diffusive transport) is constant across the garment. An interesting comparison is the total rate of heat transfer from the skin with and without condensation in the garment. The rate with condensation is 84.2 
$\mathrm{W} / \mathrm{m}^{2}$, and without condensation it is $83.0 \mathrm{~W} / \mathrm{m}^{2}$. Hence, condensation in this rather permeable garment has only a small effect on the total rate of heat transfer.

\section{Table 8 near here}

The line labeled $\mathrm{W}_{\mathrm{c}}$ in Table 8 shows the amount of water in $\mathrm{mg} / \mathrm{m}^{2}$ that condenses in each of the five layers during a one hour exposure. For example, nearly 9 $\mathrm{mg} / \mathrm{m}^{2}$ condenses in the underwear, and none condenses in the adjacent Fabric Layer 1.

In Table 9 computed temperatures are compared with measured values obtained rather imprecisely from Figs. 3 and 4 of Yoo and Kim's paper. Measured temperatures are values recorded during the nearly steady-state period of observation. Computed air temperatures are means of surface temperatures on both sides of air spaces. The differences between computed and measured temperatures at the two points closest to the skin are quite large, which would be cause for concern if the highest measured value were actually possible. However, since the skin temperature is only $33{ }^{\circ} \mathrm{C}$, the temperature in the adjacent air space (referred to as $\mathrm{T}_{1 \mathrm{a}}$ by Yoo and Kim, 2008) cannot be $35^{\circ} \mathrm{C}$, because that would require a source of heat either in the air space, or in the underwear layer. Since the first possibility seems highly unlikely, consider the second possibility. The only obvious source of heat is latent heat of vaporization released when water vapour condenses in the underwear layer. However, for that to happen, $\mathrm{p}_{2}$ would have to equal $\mathrm{p}_{\mathrm{v}, 2}$. If conduction from the underwear layer to skin accounts for $\mathrm{T}_{1 \mathrm{a}}$ being higher than $\mathrm{T}_{1}$, the temperature of the first garment layer $\left(\mathrm{T}_{2}\right)$ must be higher than $\mathrm{T}_{1 \mathrm{a}}$, which is higher than $T_{1}$. If $T_{1}<T_{2}$, then $p_{v, 1}<p_{v, 2}$. Since water does not diffuse from a region of low partial pressure to a region of higher partial pressure, it follows that condensation of water on the inner surface of the first garment layer cannot be the source of heat that causes $\mathrm{T}_{1 \mathrm{a}}$ to be higher than $\mathrm{T}_{1}$. It is only fair to note that the water vapour concentrations shown in Fig. 7 of the paper by Yoo and Kim are consistent with an air temperature above $33{ }^{\circ} \mathrm{C}$ in the first air space.

\section{Table 9 near here}

If the underwear had a very strong affinity for water, water might have been absorbed allowing the latent heat of absorption to be released while the partial pressure of water remains low. However, Yoo and Kim stated that non-hygroscopic materials were used to minimize heat of absorption effects. In addition, one would expect such effects to transient near the beginning of the experiment, and not to persist after an appreciable amount of water had condensed in the fabric.

Yoo and Kim (2008) also provided information about the amount of water condensed in the individual fabric layers. The largest accumulation of water occurred in the Fabric Layers 2 and 3, with very little condensation in Fabric Layer 1 and the Outer

Shell. Computed condensation masses in Table 9 exhibit similar characteristics, with one notable difference - the computed solution has a significant amount of water condensing 
on the inside surface of the Outer Shell. The fact that our analysis predicts a relatively small amount of condensation in the Underwear and no condensation in Fabric Layer 1 agrees with experimental observations. The computed total amount of condensed water during a 60-minute exposure is $63 \mathrm{mg} / \mathrm{m}^{2}$, which is consistent with the observed value of $61 \mathrm{mg} / \mathrm{m}^{2}$ for the $5 \mathrm{ml}$ pulse. However, that comparison is rather tentative because the amount of water available during the experiment was limited by the amount of water injected at the beginning of the experiment.

\section{Discussion}

The analysis presented in this paper, together with similar analyses published previously by Lotens, et al. (1995) and by Fukazawa, et al. (2003a), establish a rational basis for analyzing heat and water vapour transport with condensation in a cool garment. In the simplest condition, moisture condenses on the cool inner surface of an impervious outer garment, where latent heat carried by water vapour is converted to sensible heat which is transferred by conduction, convection, and radiation to the environment. We have shown that this uncomplicated process is amenable to analysis when the properties of the garment are known. When condensation occurs exclusively at one location in the garment, the temperature and partial pressure of water at that location can be determined as the intersection of a straight line (Eqn. 20) and the temperature-vapour pressure curve as shown in Fig. 3. Given those values computation of the rate of heat transfer from the skin is accomplished with ease.

The principal contribution of this paper is that it defines quantitatively sensible heat transfer and heat transport owing to diffusion of water vapor through a garment in terms of the properties of component elements of the garment, including fabric layers and intervening air spaces. In principle, our analysis is similar to that of Lotens, et al (1995) who showed that concepts presented in this paper are sufficient to account for heat loss from exercising subjects wearing either semi-permeable or impermeable garments in a cool environment. In practice, however, our analysis is different from that of Lotens, et al. in that we were able to demonstrate good agreement between computed and measured values of sensible and evaporative heat loss for several well defined systems, while Lotens, et al. used data for exercising subjects to validate their analysis.

It is obvious that our analysis requires extension before it can be applied to exercising subjects, but that is no different from using data obtained with a motionless manikin to evaluate the properties of a garment worn by exercising persons. The properties of a multi-element garment vary with time and position on the body owing to the variable air space between elements. In addition, water accumulated in one fabric layer may be transferred by wicking to adjacent layers. A third important factor neglected in our analysis is transport of heat and water out of the garment by air that ventilates the garment through various openings. Although additional analysis is required to incorporate those factors into a complete garment model for exercising subjects, it is, nevertheless, important to establish that the effect of condensation within a garment can be analyzed in a rational manner. 
The experimental system that offers the least ambiguity in terms of modeling is the cylindrical system described by Richards, et al. (2002). Physical properties of the component fabrics were measured using a flat plate system and uniform spacing was maintained between layers. The mean difference between computed and measured values of the sensible heat transfer rate (Table 6) was less than 5 percent when the skin was dry. The difference between computed and measured total heat transfer rates when the skin was wet was 12 percent, which is less than half the difference between values measured in two different laboratories (Richards, et al. 2002). In all cases except one, the computed rate of heat transfer was smaller than the measured value. A possible explanation for the discrepancy between computed and measured values is free convection in the air space driven by a horizontal density gradient. However, since the Rayleigh number for all of the cases considered was less than 1,000, it unlikely that free convection in the annular air space contributed significantly to transport of heat and water vapor (Wakitani, 1997).

Analysis of the manikin system studied by Havenith, et al. (2008) clearly presents a problem because the air space on either side of the underwear varies over the surface of the manikin. Havenith, et al. (2008) evaluated three garments, permeable, semipermeable, and impermeable, at ambient temperatures of $10^{\circ} \mathrm{C}$ and $20{ }^{\circ} \mathrm{C}$, which were cool enough to cause condensation within the garment. The mean difference between computed and measured values of the total rate of heat transfer from the skin for those six systems is 9 percent. Heat loss from the skin owing to sensible heat transfer and evaporative cooling are also shown in Table 4, but computed and measured values are not strictly comparable. Values of the sensible and evaporative heat transfer rates reported by Havenith, et al. were determined by subtracting the rate of sensible heat transfer measured on a dry manikin from the total rate of heat transfer measured with the skin wet. However, calculated values shown in Table 2 indicate that sensible heat transfer from the skin is reduced by condensation within the garment. One would expect computed values of the rate of sensible heat loss from the skin to be smaller than corresponding measured values, which is true of the semi-permeable and impermeable garments. One would also expect computed values of the rate of evaporative cooling to be larger than corresponding measured values, but that is not true.

A simple analysis based on condensation at a single location failed to provide an acceptable representation of the more complicated five-fabric system studied by Yoo and Kim (2008). However, we were able to develop an iterative numerical analysis that did yield temperatures, partial pressures of water, and vapour flow rates consistent with experimental observations. The numerical analysis was based on four criteria that were completely consistent with the physical principles stated by Lotens, et al (1995). The only difference was that the numerical method permits condensation at several different locations within the garment, which definitely occurred in the system studied by Yoo and Kim (2008).

Another important contribution of this paper is the analysis of evaporative cooling under the usual physiological condition of specified sweat secretion, instead at a specified partial pressure of water at the skin. Manikin experiments can be conducted either way, 
and the relationship between results obtained using the two approaches is not always apparent. Moreover, one must be careful in applying results measured with a specified partial pressure at the skin to human subjects who regulate the rate of sweat secretion. The discussion related to Fig. 4 should help to resolve those questions.

\section{Conclusions}

While simultaneous transfer of heat and water through a multi-layer garment can be complicated in a cool ambient environment, especially when the outer garment is relatively impervious to water vapour, the process is amenable to analysis based on a few well-established physical principles. Employing such an analysis is relatively straightforward for simple two-layer systems, answers many previously unanswered questions about this process, and may prevent large errors in heat stress assessment caused by neglecting condensation processes in clothing.

\section{References}

Bird RB, Stewart WE, Lightfoot EN (2001) Transport Phenomena, $2^{\text {nd }}$ edition, John Wiley, New York

de Dear RJ, Arens E, Hui Z, Oguro M (1996) Convective and radiative heat transfer coefficients for individual human body segments. Int J Biometeorol 40: 141-156

Farnworth B (1986) A numerical model of the combined diffusion of heat and water vapour through clothing. Textile Res J 77: 653-665

Fukazawa T, Kawamura H, Tochihara Y, Tamura T (2003a) Water vapour transport through textiles and condensation in clothes at high altitudes - combined influence of temperature and pressure simulating altitude. Textile Res J 73: 657-663

Fukazawa T, Kawamura H, Tochihara Y, Tamura T (2003b) Experiment and analysis of combined heat and water vapour transfer through clothes with condensation. Textile Res J 73: 774-780

Havenith G, Richards MG, Wang X, Broede P, Candas V, den Hartog E, Holmer I, Kuklane K, Meinander H, Nocker W (2008) Apparent latent heat of evaporation from clothing: attenuation and "heat pipe" effects. J Appl Physiol 104: 142-149

Lotens, WA, van de Linde FJG, Havenith G (1995) effects of condensation in clothing on heat transfer. Ergonomics 38: 1114-1131

Nishi Y, Gagge AP (1970) Direct evaluation of convective heat transfer coefficient by naphthalene sublimation. J Appl Physiol 29: 830-838 
Richards M, Meinander H, Broede P, Candas V, den Hartog E, Holmer, I, Nocker W, Havenith G (2002) Study of materials to investigate the effects of moisture on the heat transfer through protective clothing. Report on Project ThermProject, Contract No. G6RD-CT-2002-00846, EMPA Materials science and Technology, Switzerland

Rumford, B (1804) An enquiry concerning the nature of heat, and the mode of its communication. Phil. Trans. Royal Soc. of London 94: 77-182

Wakitani S (1997) Development of multicellular solutions in natural convection in an airfilled vertical cavity. J Heat Transfer 119: 97-101

Yoo S, Kim E (2008) Effects of multilayer clothing system array on water vapor transfer and condensation in cold weather clothing ensemble. Textile Res. J. 78: 189-197

\section{TABLES}

Table 1. Resistances for heat transfer and water vapour transport of garments evaluated by Havenith, et al. (2008)

\begin{tabular}{|l|c|c|}
\hline \multicolumn{1}{|c|}{ Garment } & $\mathrm{R}_{\mathrm{c}}\left(\mathrm{m}^{2} \mathrm{~K} / \mathrm{W}\right)$ & $\mathrm{R}_{\mathrm{e}}\left(\mathrm{m}^{2} \mathrm{~Pa} / \mathrm{W}\right)$ \\
\hline Polypropylene underwear $*$ & 0.026 & 3.7 \\
\hline Permeable outerwear & 0.025 & 5.6 \\
\hline Semi-permeable outerwear & 0.023 & 18.6 \\
\hline PVC coated outerwear $*$ & 0.007 & $1,000.0$ \\
\hline $1 \mathrm{~mm}$ interior air space $*$ & 0.120 & 21.8 \\
\hline External boundary Layer $*$ & 0.096 & 9.0 \\
\hline
\end{tabular}


Table 2. Calculated temperatures, water partial pressures, and heat transfer rates in the Reference Garment when the ambient temperature is $10{ }^{\circ} \mathrm{C}$ and $\mathrm{p}_{1}=\mathrm{p}_{\mathrm{v}, 1}$

\begin{tabular}{|l|r|r|r|r|r|}
\hline Node & 1 & 2 & 3 & 4 & 5 \\
\hline \multicolumn{7}{|c|}{ Without condensation } \\
\hline Temperature $\left({ }^{\circ} \mathrm{C}\right)$ & 34.0 & 31.5 & 19.9 & 19.3 & 10.0 \\
\hline $\begin{array}{l}\text { Partial pressure of } \\
\text { water }(\mathrm{kPa})\end{array}$ & 5.32 & 5.31 & 5.21 & 1.04 & 1.00 \\
\hline $\mathrm{Q}_{\mathrm{c}, \mathrm{i}}\left(\mathrm{W} / \mathrm{m}^{2}\right)$ & 96.2 & 96.2 & 96.2 & 96.2 & \\
\hline $\mathrm{Q}_{\mathrm{e}, \mathrm{i}}\left(\mathrm{W} / \mathrm{m}^{2}\right)$ & 4.2 & 4.2 & 4.2 & 4.2 & \\
\hline \multicolumn{7}{|c|}{ With condensation } \\
\hline Temperature $\left({ }^{\circ} \mathrm{C}\right)$ & 34.0 & 32.4 & 25.0 & 24.0 & 10.0 \\
\hline $\begin{array}{l}\text { Partial pressure of } \\
\text { water }(\mathrm{kPa})\end{array}$ & 5.32 & 5.01 & 3.16 & 1.01 & 1.00 \\
\hline $\mathrm{Q}_{\mathrm{c}, \mathrm{i}}\left(\mathrm{W} / \mathrm{m}^{2}\right)$ & 61.8 & 61.8 & 145.1 & 145.1 & \\
\hline $\mathrm{Q}_{\mathrm{e}, \mathrm{i}}\left(\mathrm{W} / \mathrm{m}^{2}\right)$ & 85.5 & 85.5 & 2.2 & 2.2 & \\
\hline
\end{tabular}

Table 3. Comparison of measured and computed (within parentheses) rates of evaporative cooling owing to moisture transfer to the environment. Heat transfer rates are in $\mathrm{W} / \mathrm{m}^{2}$.

\begin{tabular}{|l|c|c|c|}
\hline Ambient temperature $\left({ }^{\circ} \mathrm{C}\right)$ & 10 & 20 & 34 \\
\hline \multicolumn{1}{|c|}{ Outer garment } & & & \\
\hline Permeable & $120(104)$ & $131(103)$ & $126(103)$ \\
\hline Semi-permeable & $98(79)$ & $108(79)$ & $98(79)$ \\
\hline Impermeable & $20(4)$ & $17(4)$ & $10(4)$ \\
\hline
\end{tabular}


Table 4. Comparison of measured and computed (within parentheses) components of heat loss from the skin for the garments evaluated by Havenith, et al. (2008). Heat transfer rates are in $\mathrm{W} / \mathrm{m}^{2}$.

\begin{tabular}{|l|c|c|c|}
\hline Ambient temperature $\left({ }^{\circ} \mathrm{C}\right)$ & 10 & 20 & 34 \\
\hline Outer garment & & & \\
\hline & & & \\
\hline Permeable & & & \\
\hline Sensible & $81(84)$ & $46(52)$ & $0(0)$ \\
\hline Evaporation & $122(109)$ & $119(106)$ & $109(103)$ \\
\hline Total & $203(193)$ & $165(158)$ & $109(103)$ \\
\hline & & & \\
\hline Semi-permeable & & & \\
\hline Sensible & $82(74)$ & $50(44)$ & $0(0)$ \\
\hline Evaporation & $110(100)$ & $103(90)$ & $76(79)$ \\
\hline Total & $192(174)$ & $153(134)$ & $76(79)$ \\
\hline & & & \\
\hline Impermeable & & & \\
\hline Sensible & $89(62)$ & $49(37)$ & $0(0)$ \\
\hline Evaporation & $79(87)$ & $57(55)$ & $13(4)$ \\
\hline Total & $168(149)$ & $106(92)$ & $13(4)$ \\
\hline
\end{tabular}

Table 5. Resistances for heat transfer and water vapour transport of two garments evaluated by Richards, et al. (2002)

\begin{tabular}{|l|c|c|}
\hline \multicolumn{1}{|c|}{ Garment } & $\mathrm{R}_{\mathrm{c}}\left(\mathrm{m}^{2} \mathrm{~K} / \mathrm{W}\right)$ & $\mathrm{R}_{\mathrm{e}}\left(\mathrm{m}^{2} \mathrm{~Pa} / \mathrm{W}\right)$ \\
\hline Cotton underwear & 0.014 & 3.5 \\
\hline Semi-permeable outerwear & 0.023 & 18.6 \\
\hline PVC coated outerwear & 0.007 & $10,000.0$ \\
\hline $0.8 \mathrm{~mm}$ interior air space & 0.111 & 17.4 \\
\hline External boundary Layer & 0.075 & 7.4 \\
\hline
\end{tabular}


Table 6. Comparison of measured and computed (within parentheses) heat transfer rates on the sweating cylinder system of Richards, et al. (2002)

\begin{tabular}{|c|c|c|c|c|}
\hline & $\mathrm{T}_{\text {amb }}\left({ }^{\circ} \mathrm{C}\right)$ & $\mathrm{Q}_{\text {cond }}\left(\mathrm{W} / \mathrm{m}^{2}\right)$ & $\mathrm{Q}_{\text {evap }}\left(\mathrm{W} / \mathrm{m}^{2}\right)$ & $\mathrm{Q}_{\text {total }}\left(\mathrm{W} / \mathrm{m}^{2}\right)$ \\
\hline COT-SEMI & & & & \\
\hline Dry skin & 10 & $121(112)$ & $0(0)$ & $121(112)$ \\
\hline Dry skin & 20 & $77(69)$ & $0(0)$ & $77(69)$ \\
\hline & & & & \\
\hline Wet skin & 10 & $(91)$ & $(132)$ & $248(223)$ \\
\hline Wet skin & 20 & $(63)$ & $(97)$ & $193(160)$ \\
\hline & & & & \\
\hline COT-IMP & & & & \\
\hline Dry skin & 10 & $128(121)$ & $0(0)$ & $128(121)$ \\
\hline Dry skin & 20 & $75(75)$ & $0(0)$ & $75(75)$ \\
\hline & & & $(115)$ & $219(191)$ \\
\hline Wet skin & 10 & $(76)$ & $(73)$ & $147(119)$ \\
\hline Wet skin & 20 & $(46)$ & &
\end{tabular}

Table 7. Properties of the five layer Array A studied by Yoo and Kim (2008)

\begin{tabular}{|l|c|c|c|}
\hline Region & Nodes & $\mathrm{R}_{\mathrm{c}}\left(\mathrm{m}^{2} \mathrm{~K} / \mathrm{W}\right)$ & $\mathrm{R}_{\mathrm{e}}\left(\mathrm{m}^{2} \mathrm{~Pa} / \mathrm{W}\right)$ \\
\hline & & & \\
\hline 9 mm air space & $1-2$ & 0.157 & 16.3 \\
\hline Underwear & $2-3$ & 0.014 & 3.5 \\
\hline Fabric Layer 1 & $3-4$ & 0.083 & 11.7 \\
\hline 7 mm air space & $4-5$ & 0.168 & 13.4 \\
\hline fabric Layer 2 & $5-6$ & 0.083 & 11.7 \\
\hline 7 mm air space & $6-7$ & 0.184 & 14.4 \\
\hline Fabric Layer 3 & $7-8$ & 0.083 & 11.7 \\
\hline 8 mm air space & $8-9$ & 0.247 & 20.7 \\
\hline Outer shell & $9-10$ & 0.019 & 7.3 \\
\hline Ambient air & $10-11$ & 0.100 & 12.2 \\
\hline
\end{tabular}


Table 8. Computed values for Array A studied by Yoo and Kim (2008) with a skin temperature of $33{ }^{\circ} \mathrm{C}$ and an ambient air temperature of $-15^{\circ} \mathrm{C}$.

\begin{tabular}{|ll|r|r|r|r|r|r|r|r|r|r|r|}
\hline \multicolumn{2}{|c|}{ Node } & 1 & 2 & 3 & 4 & 5 & 6 & 7 & 8 & 9 & 10 & 11 \\
\hline & & & & & & & & & & & \\
\hline $\mathrm{T}_{\mathrm{i}}\left({ }^{\circ} \mathrm{C}\right)$ & 33.00 & 29.22 & 28.80 & 26.30 & 21.24 & 18.09 & 11.09 & 6.56 & -7.03 & -8.30 & -15.00 \\
\hline $\mathrm{p}_{\mathrm{i}}(\mathrm{kPa})$ & 5.03 & 4.06 & 3.87 & 3.24 & 2.52 & 1.98 & 1.32 & 0.98 & 0.37 & 0.25 & 0.04 \\
\hline $\mathrm{p}_{\mathrm{v}, \mathrm{i}}(\mathrm{kPa})$ & 5.03 & 4.06 & 3.96 & 3.42 & 2.52 & 2.07 & 1.32 & 0.98 & 0.37 & 0.34 & 0.21 \\
\hline $\mathrm{Q}_{\mathrm{c}, \mathrm{i}}\left(\mathrm{W} / \mathrm{m}^{2}\right)$ & & 24.11 & 30.14 & 30.14 & 30.14 & 38.00 & 38.00 & 54.52 & 54.92 & 66.98 & 66.98 \\
\hline $\mathrm{Q}_{\mathrm{e}, \mathrm{i}}\left(\mathrm{W} / \mathrm{m}^{2}\right)$ & & 60.06 & 54.03 & 54.03 & 54.03 & 46.16 & 46.16 & 29.65 & 29.25 & 17.19 & 17.19 \\
\hline $\mathrm{E}_{\mathrm{i}}\left(\mathrm{gm} / \mathrm{s} \mathrm{m}^{2}\right)$ & & 24.74 & 22.25 & 22.25 & 22.25 & 19.01 & 19.01 & 12.21 & 12.05 & 7.08 & 7.08 \\
\hline \multicolumn{2}{l}{} & & & & & & & & & & & \\
\hline $\mathrm{W}_{\mathrm{c}}\left(\mathrm{mg} / \mathrm{m}^{2}\right)$ & & & 8.99 & 0.00 & & 11.73 & & 24.62 & & 17.98 & \\
\hline
\end{tabular}

Table 9. Comparison of computed and measured temperatures for Yoo and Kim's Array A with a skin temperature of $33^{\circ} \mathrm{C}$ and an ambient air temperature of -15 oC.

\begin{tabular}{|l|c|c|}
\hline \multicolumn{1}{|c|}{ Location } & \multicolumn{2}{|c|}{ Temperatures $\left({ }^{\circ} \mathrm{C}\right)$} \\
\hline & Measured & Computed \\
\hline Air between Nodes 1 and 2 & 35 & 31.1 \\
\hline Air between Nodes 4 and 5 & 28 & 23.8 \\
\hline Surface at Node 5 & 22 & 21.2 \\
\hline Surface at Node 6 & 20 & 18.1 \\
\hline Air between Nodes 6 and 7 & 16 & 14.1 \\
\hline Air between Nodes 8 and 9 & -1 & -0.2 \\
\hline
\end{tabular}


Table 10. Notation

$\underline{\text { Symbol Definition }}$

$\mathrm{h}_{\mathrm{c}} \quad$ convective heat transfer coefficient

$\underline{\text { SI units }}$

$\mathrm{h}_{\mathrm{r}} \quad$ radiative heat transfer coefficient

$\mathrm{W} /\left(\mathrm{m}^{2} \mathrm{~K}\right)$

$\mathrm{k}_{\mathrm{a}} \quad$ thermal conductivity of air

$\mathrm{W} /\left(\mathrm{m}^{2} \mathrm{~K}\right)$

$\dot{m}_{i c} \quad$ rate of condensation at Node ic

$\mathrm{W} /(\mathrm{m} \mathrm{K})$

$\mathrm{p}_{\mathrm{o}} \quad$ standard pressure

$\mathrm{kg} /\left(\mathrm{s} \mathrm{m}^{2}\right)$

$\mathrm{p}_{1, \mathrm{~m}} \quad$ minimum partial pressure of water on the skin for which condensation occurs in the garment $\quad \mathrm{Pa}$

$\mathrm{p}_{\mathrm{i}} \quad$ partial pressure of water at Node $\mathrm{i} \quad \mathrm{Pa}$

$\mathrm{p}_{\mathrm{v}, \mathrm{i}} \quad$ vapour pressure of water at temperature $\mathrm{T}_{\mathrm{i}} \quad \mathrm{Pa}$

$p_{v, i c} \quad$ vapour pressure of water at temperature $T_{i c} \quad P a$

$\mathrm{x}_{\mathrm{a}}$ thickness of air layer $\mathrm{m}$

$\mathrm{C}_{\mathrm{L}} \quad$ Lewis coefficient $\mathrm{K} / \mathrm{Pa}$

D diffusivity of water in air $\mathrm{m}^{2} / \mathrm{s}$

$\mathrm{E}_{\mathrm{i}} \quad$ rate of water transport from Node i to Node i+1 $\mathrm{kg} /\left(\mathrm{s} \mathrm{m}^{2}\right)$

$\mathrm{E}_{\mathrm{a}} \quad$ rate of water transport across an air space $\mathrm{kg} /\left(\mathrm{s} \mathrm{m}^{2}\right)$

$\mathrm{Q}_{\mathrm{c}, \mathrm{i}}$ rate of sensible heat transfer from Node i to Node i+1 W/ $/ \mathrm{m}^{2}$

$\mathrm{Q}_{\mathrm{a}} \quad$ rate of sensible heat transfer across an air space $\mathrm{W} / \mathrm{m}^{2}$

$Q_{e, i} \quad$ rate of enthalpy flow from Node i to Node $i+1$ owing to diffusion of water vapour $\quad \mathrm{W} / \mathrm{m}^{2}$

$\mathrm{Q}_{\mathrm{sk}}$ total rate of heat removal from skin $\mathrm{W} / \mathrm{m}^{2}$

$\mathrm{R}_{\mathrm{c}, \mathrm{i}} \quad$ resistance to sensible heat transfer between Nodes $i$ and $i+1$

$\hat{R}_{c, i} \quad$ resistance to sensible heat transfer between the skin and Node i+1

$\mathrm{R}_{\mathrm{c}, \mathrm{bl}} \quad$ resistance to sensible heat transfer at the outer surface of the garment

$\mathrm{R}_{\mathrm{e}, \mathrm{i}} \quad$ resistance to evaporative heat transfer between Nodes $\mathrm{i}$ and $\mathrm{i}+1$

$\hat{R}_{e, i} \quad$ resistance to evaporative heat transfer between the skin and Node $\mathrm{i}+1 \quad \mathrm{~m}^{2} \mathrm{~Pa} / \mathrm{W}$

$\mathrm{R}_{\mathrm{e}, \mathrm{bl}} \quad$ resistance to evaporative heat transfer at the outer surface of the garment $\quad \mathrm{m}^{2} \mathrm{~Pa} / \mathrm{W}$

$\mathrm{T}_{\mathrm{i}} \quad$ temperature at Node $\mathrm{i} \quad \mathrm{K}\left({ }^{\circ} \mathrm{C}\right)$

$\mathrm{T}_{\mathrm{ic}} \quad$ temperature at the node where condensation occurs $\quad \mathrm{K}\left({ }^{\circ} \mathrm{C}\right)$

$\mathrm{T}_{\mathrm{a}}$ temperature in the air space $\mathrm{K}\left({ }^{\circ} \mathrm{C}\right)$

$\mathrm{W}_{\mathrm{c}} \quad$ amount of water condensed in a garment $\mathrm{mg} /\left(\mathrm{m}^{2}\right)$

$\varepsilon$ emissivity dimensionless

$\lambda \quad$ latent heat of vaporization of water $\quad \mathrm{J} / \mathrm{kg}$

$\sigma \quad$ Stefan-Boltzmann constant $\quad \mathrm{W} /\left(\mathrm{m}^{2} \mathrm{~K}^{4}\right)$

$\rho_{\mathrm{H}_{2} \mathrm{O}} \quad$ density of water vapour under standard conditions $\quad \mathrm{kg} /$ 


\section{Figure captions}

Figure 1. Placement of five nodes for the two-layer Reference Garment.

Figure 2. Partial pressure of water and temperature within the Reference Garment when the ambient temperature is $10{ }^{\circ} \mathrm{C}$. The heavy solid line is the temperature-vapour pressure curve for water. Values are plotted for five nodes starting with Node 1 at $\mathrm{T}=34$ ${ }^{\circ} \mathrm{C}$ and ending with Node 5 at $\mathrm{T}=10{ }^{\circ} \mathrm{C}$. Filled circles denote values without condensation in the garment, and filled triangles denote values with condensation at Node 3. Open triangles denote values when $\mathrm{p}_{1}=2.36 \mathrm{kPa}$, the minimum value for which condensation occurs.

Figure 3. Graphical construction to determine $T_{i c}$ and $p_{v \text {,ic }}$ when condensation occurs at Node 3 in the Reference Garment. The heavy line is the temperature-vapour pressure curve and the light line is the straight line defined by Eqn. $20 . \mathrm{T}_{\mathrm{ic}}=25.0{ }^{\circ} \mathrm{C}$ and $\mathrm{p}_{\mathrm{ic}}=3.16 \mathrm{kPa}$.

Figure 4. Total rate of heat loss from the skin as a function of the partial pressure of water on the skin for the Reference Garment when the ambient temperature is $10{ }^{\circ} \mathrm{C}$. The heavy line represents the actual rate of heat loss from the skin, and the light line is the rate of heat loss that would occur if there were no condensation in the garment. 


\section{Figures}

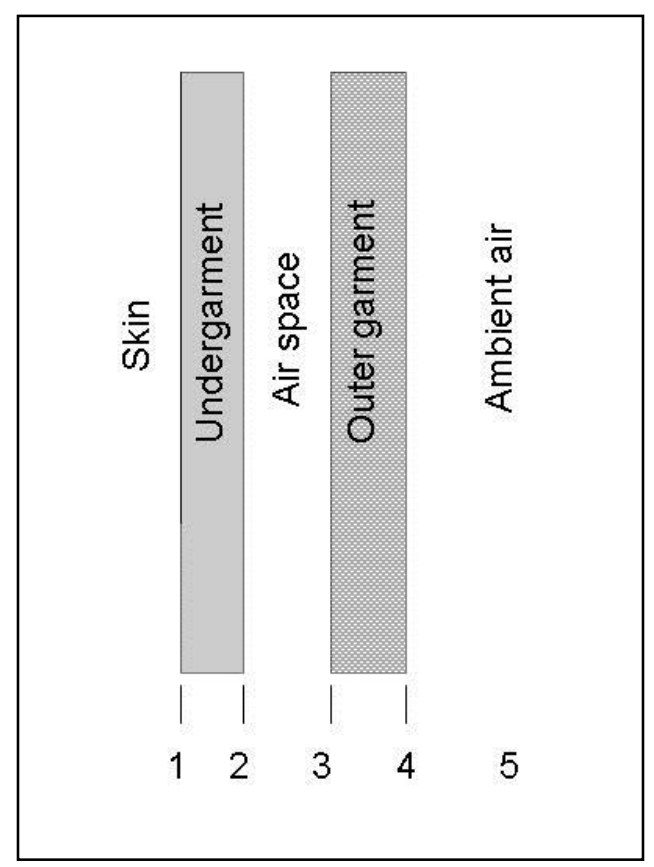

Figure 1. Placement of five nodes for the two-layer Reference Garment. 


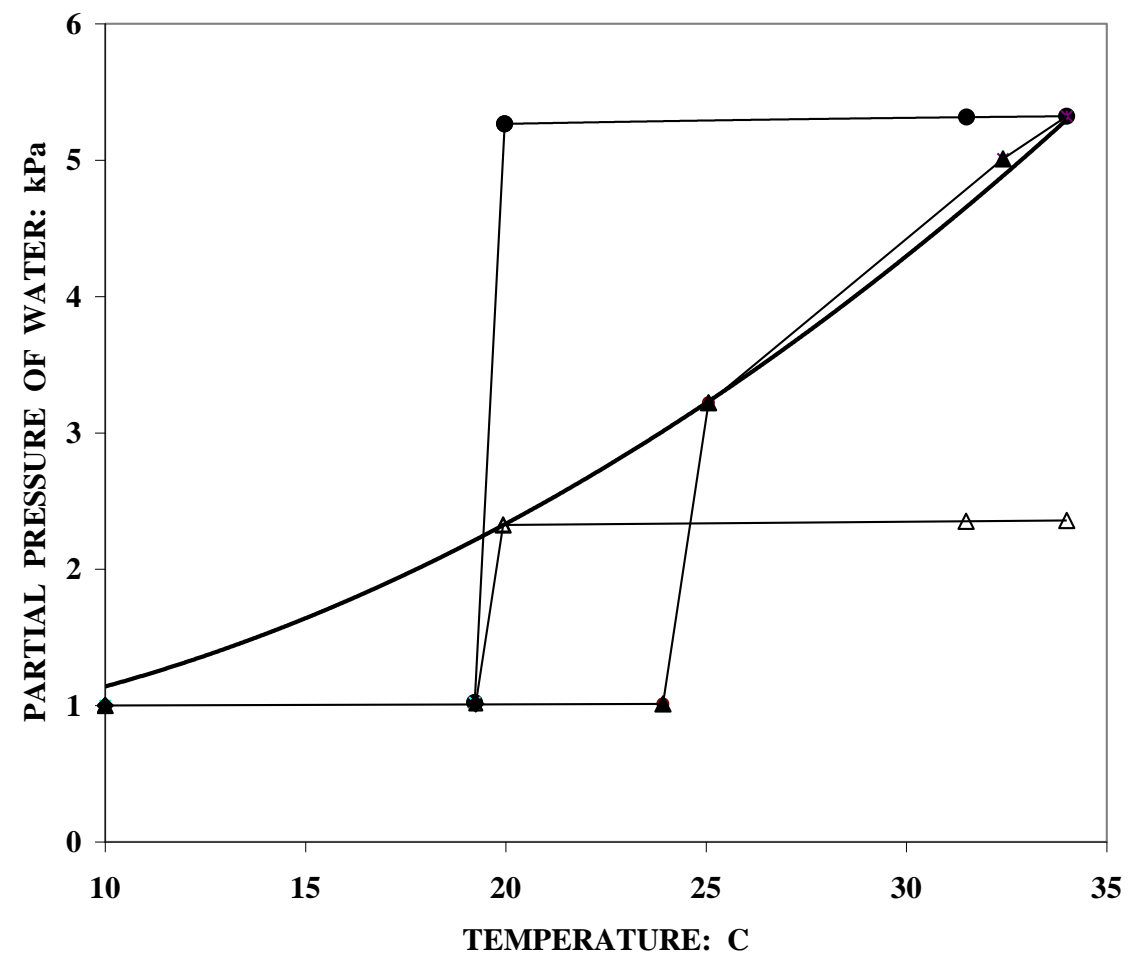

Figure 2. Partial pressure of water and temperature within the Reference Garment when the ambient temperature is $10{ }^{\circ} \mathrm{C}$. The heavy solid line is the temperature-vapour pressure curve for water. Values are plotted for five nodes starting with Node 1 at $\mathrm{T}=34$ ${ }^{\circ} \mathrm{C}$ and ending with Node 5 at $\mathrm{T}=10{ }^{\circ} \mathrm{C}$. Filled circles denote values without condensation in the garment, and filled triangles denote values with condensation at Node 3. Open triangles denote values when $\mathrm{p}_{1}=2.36 \mathrm{kPa}$, the minimum value for which condensation occurs. 


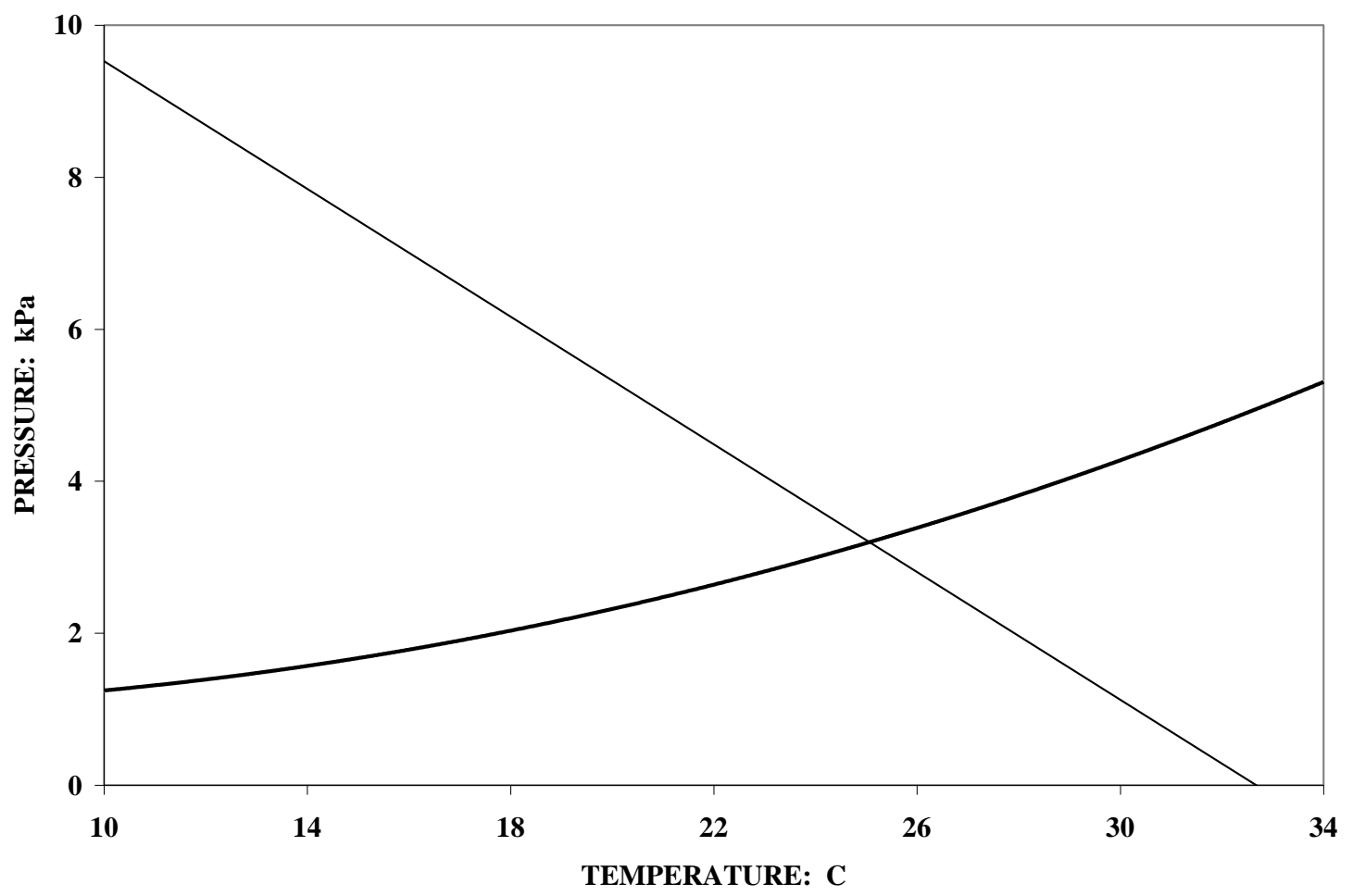

Figure 3. Graphical construction to determine $\mathrm{T}_{\mathrm{ic}}$ and $\mathrm{p}_{\mathrm{v}, \mathrm{ic}}$ when condensation occurs at Node 3 in the Reference Garment. The heavy line is the temperature-vapour pressure curve and the light line is the straight line defined by Eqn. $20 . \mathrm{T}_{\mathrm{ic}}=25.0{ }^{\circ} \mathrm{C}$ and $\mathrm{p}_{\mathrm{ic}}=$ $3.16 \mathrm{kPa}$. 


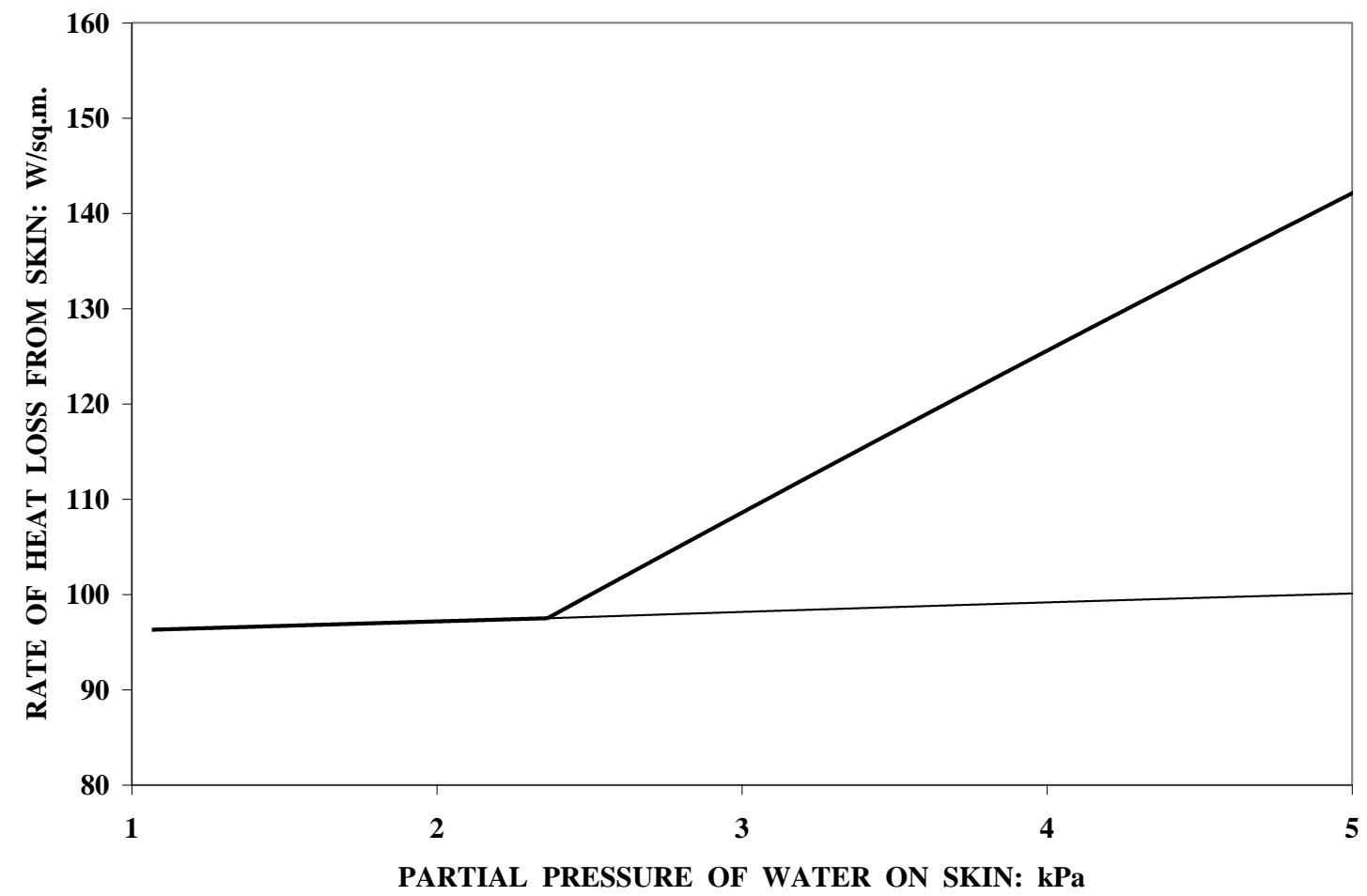

Figure 4. Total rate of heat loss from the skin as a function of the partial pressure of water on the skin for the Reference Garment when the ambient temperature is $10^{\circ} \mathrm{C}$. The heavy line represents the actual rate of heat loss from the skin, and the light line is the rate of heat loss that would occur if there were no condensation in the garment. 